\title{
Are rival theories of smoking underdetermined?
}

\author{
Robert S. Goldfarb, Thomas C. Leonard and \\ Steven M. Suranovic
}

\begin{abstract}
Some empirically minded philosophers of science argue that the evidence should choose the best theory from among theoretical rivals. However, the evidence may not speak clearly, a problem of 'underdetermination of theory by data'. We examine this problem in a concrete setting, rival theories of smoking behaviour. We investigate whether several uncontested pieces of empirical evidence allow us to choose between two competing theoretical perspectives on smoking, rational choice and non-rational choice, respectively. Next, we develop a more refined taxonom y of smoking theories, and consider the consequences for theory testing. Finally, we examine some normative aspects of theory choice involving the appropriate scope of government action.
\end{abstract}

Keywords: underdetermination of theory by data, empirical testing, theory choice, rational choice theory, smoking, paternalism.

\section{INTRODUCTION}

Empirically minded philosophers of science have long argued that the evidence should choose the best theory from among theoretical rivals. But the evidence may not speak clearly. 'Facts' may be obscured by measurement error or problems of data interpretation. Or one of the competing theories may be compatible with one set of data or evidence, while a rival theory is compatible with different evidence. Even when facts do seem clear, the competing theories may be empirically equivalent - that is, have identical empirical consequences - so that the available evidence appears to support or disconfirm the rivals equally. These familiar difficulties are sometimes referred to as a problem of 'underdetermination of theory by data' (UTD) - the failure of evidence to select a best theory from among the theoretical rivals.

This paper examines the underdetermination problem in a concrete setting, rival theories of smoking behaviour. There are a number of reasons why this case is especially interesting. First, rival theories of smoking are from a wide range of disciplines - medicine, biochemistry, public health, economics, sociology and law, among others - and often have different empirical implications. Second, the subject under study, smoking behaviours, is narrowly focused and there is wide agreement on what is to be explained. 
Both the narrowness and the agreement suggest that underdetermination difficulties might be minimal, so that the data might help us to choose among theories. Third, the empirical evidence is both extensive and largely uncontested. Theorists generally regard rivals' data as factual, so that disputes ordinarily focus on theory testing - what the data imply for theory, rather than what the data are. Finally, a methodologically interesting complication is that rival theorists differ not only on smoking policy prescriptions, but also disagree more generally about the scope for legitimate government action.

Cigarette smoking is widely regarded as a health problem. The US Surgeon General indicates that it is the leading cause of preventable death and disease in the USA. ${ }^{1}$ Smoking is also highly habit-forming, and imposes costs on nonsmokers. Among the different theoretical perspectives on smoking, these (and other related) claims are essentially regarded as facts. There is, however, widespread disagreement as to why people smoke (or do not) and whether smoking should be seen as a private or as a public health matter. Public health officials argue that 'smoking . . . is the single most important public health issue of our time' (U SD HHS, 1982, emphasis added), while many economists say that (adult) smoking should remain a private matter except if there are market failures such as costs external to smokers, or insufficient or inaccurate information on health risks.

To investigate the extent of the underdetermination problem in the smoking case, and to see whether theoretical and policy disagreements over smoking are due to underdetermination, we proceed as follows. First, we sketch some philosophy of science preliminaries. In Section 3 we introduce two rival theoretical perspectives on smoking, rational and non-rational, respectively. In Section 4 we examine five pieces of empirical evidence with respect to the rational and non-rational alternatives. To what extent do these pieces of evidence allow us to choose among competing theories? In Section 5 we develop a more refined taxonomy of smoking theories, and consider the consequences for theory testing. Lastly, in Section 6 we consider some additional aspects of choosing among rival theories of smoking.

\section{SOME PRELIMINARIES}

Theories are regarded as empirically equivalent when they have identical empirical consequences (Laudan and Leplin, 1991: 451). Since it is easy to generate theoretical 'alternatives' by trivially changing a current theory (Cross, 1998), there are, logically at least, an indefinite number of empirically equivalent theories. An indefinite number of rival theories entailing the same empirical consequences does seem to imply UTD, since any actual evidence would support (or disconfirm) all rivals equally.

Some influential views of scientific knowledge hold that the empirical equivalence of rival theories does indeed imply UTD. Quine (1953), for 
example, reads empirical equivalence as making rival theories epistemologically equal, thereby reducing theory choice to wholly non-evidential (his term is 'pragmatic') considerations. Quine's interpreters in the sociology of science have extended this sceptical line of argument, claiming that underdetermination amounts to undetermination of theory by empirical evidence. Call this position strong UTD.

For proponents of strong UTD, empirical evidence never influences theory choice. Scientists may (falsely) invoke the influence of data for rhetorical purposes, but, says Harry Collins (1981: 3), 'the natural world has a small or non-existent role in the construction of scientific knowledge'. '[W] can never use . . Nature', argues Latour (1987: 99), 'to explain how and why a [scientific] controversy has been settled'. Some even make a methodological injunction out of the proposition: 'explanations should be developed within the assumption that the real world does not affect what the scientist believes about it'. (Collins and Yearly 1992: 372). ${ }^{2}$ Proponents of strong UTD also generally emphasize the social subset of non-evidential determinants of scientific belief - social class, ideology, financial gain, and so on - whereas others (Quine included) invoke more traditional non-evidential criteria of theory choice, such as parsimony, or internal consistency, or congruency with other theories regarded as true.

Weaker versions of UTD, which is to say all other versions, are adopted by those less sceptical of the scientific enterprise. Most theorists of science acknowledge that underdetermination can occur in some settings, but they deny the strong claim that UTD universally makes all theoretical rivals equally good. ${ }^{3}$ It is not unusual in science for the data to be sketchy, or contested or non-existent. But to recognize that actual data sometimes fail to choose clearly makes a far weaker claim than the strong UTD hypothesis that no evidence, even when ideal, can choose among theories. Though philosophers of science typically mean UTD to apply to situations of empirical equivalence, we define weak UTD in a broader sense: all non-strong UTD instances where the data fail to choose. This includes the case of theoretical rivals that are not empirically equivalent, but are regarded thus far as, to use Van Fraassen's term, empirically adequate (van Fraassen, 1980).

In sum, the strong version of UTD says that no evidence, even ideal evidence, can adjudicate among rival theories; hence evidentially based theory choice is impossible in principle. The weak version of UTD denies that all rival theories are always in principle equally good, while emphasizing that evidence at times does not adjudicate among rival theories. Thus, evidentiallybased theory choice may be difficult in practice. Two examples might be when the data are inadequate, or instead when the data are good, but the theory choice criteria indicate a tie. ${ }^{4}$

So how do these issues about the ability of evidence to help us choose among theories manifest themselves in the case of rival theories of smoking? What can we learn about the interaction of evidence with theory choice by 
examining this concrete, narrowly focused case? We begin by considering two rival theoretical perspectives about smoking behaviour.

\section{RATIONAL VERSUS NON-RATIONAL THEORIES OF SMOKING}

In rational-choice theories of smoking, agents make purposeful, reasoned choices consistent with given preferences. Rational agents evaluate costs and benefits, and respond to changes therein, so rational explanations logically allow that one can be better off smoking, i.e. that the costs smokers risk can be exceeded by the benefits of smoking. The taste and feel of tobacco smoke can be pleasurable; smoking's rituals are often social, and can be comforting, even sensual (Klein, 1993); and nicotine, rare among drugs, has a homeostatic affect on mood - it calms when one is nervous, stimulates when one is sluggish.

Smoking introduces two complications for the rational choice theorist: (i) intertemporal effects; and (ii) nicotine addiction. ${ }^{5}$ Intertemporal effects arise because smoking decisions and utility consequences are partly separate in time. Current and prior cigarette consumption (the consumption 'stock') increases future health risks and withdrawal costs. The consumption stock also affects future benefits - the pleasure of smoking can increase or decrease with past consumption, depending upon the relative effects of tolerance and reinforcement. Since smoking entails future costs and benefits, the rational agent must form some expectations and a means for evaluating them in present terms. It is thus not merely future prices and income that the agent must forecast, but also dynamically contingent utility effects, along with a method for discounting projected consumption paths. The accuracy and completeness of expectations, and discounting methods, can vary across rational-choice models, but all rational smoking theories make agents forward looking in some measure, not myopic.

Rational smoking theories treat nicotine addiction in different ways, but all make it at least partly internal to the cost-benefit decision process. In some models addiction is chosen, eyes open (Becker and Murphy, 1988), while in other models addiction is more a byproduct of ex ante uncertainty as to whether one is the 'addictive type' (Orphanides and Zervos, 1995) or of dynamically inconsistent preferences (Suranovic et al., 1999). But in rational theories of smoking, nicotine addiction is not regarded as a mistake and neither is it seen as 'external' to decision making, i.e. as an avolitional compulsion that overwhelms the ability to choose rationally. Addiction unambiguously makes smoking hard to quit, but rational choice theorists generally do not regard smoking as different in kind from other hard-to-reverse choices, such as choosing a spouse or a career (Viscusi, 1992) or failing to maintain a low-fat diet and an exercise regimen. ${ }^{6}$ 
Non-rational choice theories of smoking, as the name suggests, are a family of approaches that quarrel with one or more aspects of the rational choice approach. They are far more diverse than are rational choice theories, but all make assumptions which imply that harmful behaviours are the product of (i) decision making incompetence, or (ii) decision making incapacitation (temporary incompetence), or both.

Decision making incompetence arises, notably, when the agent is immature or otherwise incapable of rational choices with respect to smoking. Children, for example, may be unable to fully contemplate life-threatening risk, or may lack an adequate means of discounting future costs, or may be especially susceptible to suasion, such as tobacco promotion or peer pressure. This is not inconsistent with rational choice per se; but it raises the difficult question of when children become mature enough to be deemed rational. Policies that aim to protect these incompetents from risky endeavours (driving, soldiering, sex, truancy, gambling, drinking, marriage) are sometimes referred to as 'soft' paternalism (see New, 1999; 'hard' paternalism is non-consensual interference in the self-regarding decision-making of a competent adult, intended to further his welfare, while 'soft' paternalism is reserved for incompetent adults or children).

Intervening to protect adults from themselves is more controversial. Adults may be deemed incompetent when they are entirely myopic. Chaloupka and Warner 1999 identify a class of 'myopic models of addictive behaviour'. In these models, behaviour is non-rational because it is not forward looking (following Pollack, 1975: 22): 'an individual recognizes the dependence of current addictive behaviour decisions on past consumption, but then ignores [what logically must follow] the impact of current and past choices on future consumption decisions when making current choices' ${ }^{7}$

Incapacitation holds that adults, who are ordinarily competent decision makers, have their rational faculties overwhelmed by nicotine addiction. 'Once they have started smoking regularly', says David Kessler, a former commissioner of the Food and Drug Administration, 'most smokers are in effect deprived of the choice to stop smoking'. (Sullum, 1997). The 'primrosepath' model (see Herrnstein and Prelec, 1992) combines incompetence and incapacitation in a life-cycle story: smokers take up smoking as youths owing to incompetence. When mature enough to properly ascertain a poor choice, they are already hooked and the preferred choice is foreclosed by addiction (incapacitation).

Classifying diverse perspectives on smoking using a simple rational/ non-rational dichotomy has obvious limitations. However, both because it is revealing in itself, and because it helps to motivate a subtler taxonomy, we consider the question of how one might choose between the rational choice and non-rational choice alternatives. Can evidence or data be used to show that one theory is clearly superior, or do underdetermination problems arise? 


\section{EVIDENCE AND THE CHOICE BETWEEN RATIONAL AND NON-RATIONAL THEORIES}

How might one evaluate the relative merits of the rational and non-rational approaches to smoking? There are many possible criteria for appraising rival theories. Leonard (1997: 27) provides a list of 21 different desiderata for a good theory, as proposed by distinguished commentators from economics or philosophy. ${ }^{9}$ Since our interest concerns possible UTD, we ask whether there are accepted facts that are clearly inconsistent with one of the perspectives, but not the other. We consider five pieces of empirical evidence that have been or might be invoked to challenge one view or the other: (i) consumer response to price incentives; (ii) expressed regret by smokers; (iii) brain imaging evidence; (iv) quitting behaviour; and (v) subjective risk assessment.

\subsection{Response to price incentives}

There is widespread consensus that the empirical evidence suggests that current and potential smokers respond to price incentives. Higher excise taxes, for example, decrease cigarette consumption. ${ }^{10}$ This evidence is clearly consistent with the rational choice approach, which predicts responsiveness to price changes. In contrast, a theory that emphasizes strong incapacitation would seem to rule out systematic responses consistent with the law of demand. Thus widespread demonstrated response to price appears prima facie to disconfirm a theory emphasizing strong incapacitation.

However, this preliminary verdict is incorrect. Becker (1962), the archetypical rational choice theorist, showed that, while rationality is sufficient for the law of demand, it is not necessary. ${ }^{11}$ Non-rational consumers can behave consistently with downward-sloping demand. In his model, consumers choose consumption randomly, though on their budget constraints. Prices affect the range (probability distribution) of consumption bundles available to the random chooser, so an individual may choose less or more with higher price, but, at the market level - if income is constant - aggregate consumption must fall with higher prices. It is thus scarcity in the form of budget constraints, not individual response to costs and benefits per se, that creates downward-sloping market demand curves. In theory, then, observed negative price elasticities need not be inconsistent with a view that agents are incapacitated or incompetent.

A second argument comes from Warner, who points out that animals also obey the law of demand: "drug-addicted laboratory animals do exactly the same thing when the 'price' of their drug - the number of times a lever must be pushed, for example - is increased' (Warner, 1999). These laboratory animals presumably are not purposefully evaluating expected costs and benefits, so systematic price responsiveness does not, by itself, disconfirm non-rational choice theories. 


\subsection{Smoker's regret}

Survey evidence and casual empiricism suggest that many smokers regret taking up the habit. The inconsistency of continued smoking combined with a stated desire to quit presents an empirical challenge to rational smoking theories. Hanson and Logue (1998: 1193-94), in a lengthy critique of the rational choice view, argue that 'economists . . . for the most part have failed to provide a plausible account of the apparent conflict between smokers' revealed preferences and their stated preferences'. ${ }^{12}$

However, smoker's regret does not refute the rational choice approach, depending upon what regretful smokers actually mean. If smokers mean I wish I didn't smoke', this is not inconsistent with rational choice. It means only that current choices are unpleasant. The pain of quitting can be seen as part of the cost paid for the pleasures enjoyed along the way, analogous to being overweight or hung over, or in debt. One can clearly regret that the bill has come due, but this regret does not demonstrate a non-rational choice (in lifetime terms); it just implies that much of the benefits are sunk.

Suranovic et al. (1999) and Goldbaum (2000), for example, assume that health costs arise late in life, so it can be rational to smoke when young, then quit when health costs become more proximate in time. When discounted health costs exceed current benefits, there is also the cost of quitting, which may exceed net health costs. This situation is consistent with statements like 'I'd like to quit, but I cannot'. Smoking is bad but quitting is worse. As expected net health costs continue to increase with age, they can exceed withdrawal costs, at which point the smoker quits. Moreover, as the time to rationally quit draws closer, one can regret being a smoker, because the pain of withdrawal, though rational to endure, still lies ahead.

Uncertainty can also lead to addiction and regret. Orphanides and Zervos (1995), for example, assume that the propensity for addiction is uncertain ex ante, so that potential smokers can rationally risk the possibility of addiction to obtain the usual benefits of smoking. Smokers who are unlucky and prove to be addictive types can be unhappy, ex post, without ever being nonrational. They gambled and lost. So smokers' regrets do not, by themselves, refute rational smoking. 13

\subsection{Brain imaging evidence}

There is evidence from brain imaging that addictive drug use causes biological changes in the brain (see Satel, 1999). If similar changes occur in smokers' brains, one could then read this as physical evidence of incapacitation, wherein habitual smoking alters the brain so as to 'mask' or make it difficult to act upon one's 'true' preferences.

While such evidence might seem to challenge a rational-choice approach, it need not. There are two complementary reasons why. First, since the onset of 
smoking occurs before the brain is affected by addiction, a rational choice model can still apply to the decision to begin smoking. Second, and more important, there are reasons to contest the claim that brain changes entail non-purposive, non-rational choices.

Why? Because there may not be any behavioural changes that correlate with the observed brain change, and, even if there are correlating behavioural changes, it's uncertain as to whether the behaviour or the drugs are causing brain change. (Shaffer in Lambert, 2000). Satel 1999 argues that, for illegal drugs and alcohol, there is no scientific evidence that the brain changes that come with drug exposure correlate with changed behaviour. ${ }^{14}$ She reads studies of addicts' behaviour as showing that they are capable of choice and control behaviour that is inconsistent with a brain-bound, involuntary model of addiction'. (Satal, 1999: 54). Says Satel (1999: 56), "calling addiction a chronic and relapsing disease is simply wrong ... in the general population remission from drug dependence (addiction) and drug abuse is the norm . . . relapse is not'. She cites a famous study which found that 'only $14 \%$ of [returning Vietnam War veterans] who were dependent on heroin in Vietnam - and who failed a publicized urine test at departure because they could not stop using - resumed regular heroin use back home'. ${ }^{15}$ (p. 63).

The brain imaging evidence cited refers to drugs and alcohol, not to cigarettes. But the argument above suggests that, even were there such biological changes among smokers, it would not by itself defeat the rational choice approach.

\subsection{Quitting behaviour}

Two well-established empirical facts about quitting behaviour are: (i) on any given attempt to quit, the smoker is very likely to fail; and (ii) many of those who try to quit eventually do succeed after numerous attempts. ${ }^{16}$ The first fact challenges the rational choice approach. It suggests people are unable to carry out what appear to be their intentions. But its strength as a challenge is mitigated by the second fact; many people who want to quit do succeed in doing so. The second fact, in turn, might be seen as a challenge to the nonrational choice approach. Quitting is a purposive act, showing that those addicted to nicotine are not so incapacitated that they are unable to shed the habit.

But just as the first fact does not defeat the rational choice view, the second fact does not refute a non-rational choice view. Some smokers never try to quit, and some of them may fit the non-rational paradigm. Moreover, some who try to quit repeatedly, may repeatedly fail. In summary, these facts are not sufficient to convince a reasoned advocate of one of the paradigms that the other view was definitely superior. 


\subsection{Accuracy of health risk information}

Anti-smoking advocates often argue that prospective and current smokers underestimate the health costs risked by smoking (e.g. Hanson and Logue, 1998). ${ }^{17}$ We consider two aspects of this matter: how accurate is the risk information people possess, and what are the implications for the rational and non-rational choice alternatives? Because risk assessment is subjective, the data are scarce. Two important studies (Viscusi, 1992; Shoenbaum, 1997) give mixed and partly contradictory results.

Viscusi (1992) asked 3119 respondents in 1985 to estimate the likelihood of developing lung cancer for a lifetime smoker. The average respondent put the risk at $43 \%$, which is at least a four-fold overestimate, since the actual objective risk is estimated to be between 5-10 percent. Even smokers vastly overestimated the true risk, putting the risk at 37\%. ${ }^{18}$ Viscusi also found that respondents, again including smokers, significantly over-estimate the total smoking mortality risk, that is, the risk of dying from all smoking-related causes. $^{19}$

Viscusi's result that people overestimate the dangers of smoking is partially contradicted by Shoenbaum (1997), who found that, among white men and women aged 50-62, heavy smokers (25 or more cigarettes daily) have expectations of reaching age 75 that are nearly twice as high as the true actuarial probability - that is, heavy smokers underestimate their risk of premature mortality. ${ }^{20}$ But Schoenbaum also found, and failed to emphasize, that female respondents who formerly smoked, or currently smoked fewer than 25 cigarettes daily, all overestimated their chances of dying by age 75 (Schoenbaum, 1997: 757). In fact, of the 1914 current smokers he surveyed, about $40 \%$ overestimated their chances of dying prematurely, while about $32 \%$ underestimated their odds - the remainder estimated correctly.

A neutral observer might take the two studies to show that most smokers either have accurate risk information, or overestimate the hazards of smoking, with the exception of the heaviest smokers, for whom the risks are greatest. As before these results are not decisive. Rational choicers will emphasize that nearly everybody (in the USA), smokers included, recognizes that smoking is risky, and, moreover, departures from accuracy tend to overestimate smoking risks. Non-rational choice partisans will emphasize that heavy smokers - the very people with the most to lose - tend to underestimate the hazards. ${ }^{21}$

\subsection{The problem of non-adjudicating data}

The evidence we have reviewed, while substantial, does not seem to decisively select either the rational or non-rational smoking perspective, and thus is consistent with (though does not prove) the UTD hypothesis. Why does the evidence offer so little traction? There are several (not mutually exclusive) 
alternatives - 'fuzzy' testing, Duhem-Quine type problems, opportunistic theorists, and inadequate data.

Fuzzy testing refers to the problem that evidence bears more directly on narrow hypotheses than on broad paradigmatic approaches - here, the rational and non-rational choice perspectives - from which they derive. If, for example, the evidence were to corroborate hypotheses that are rational choice in spirit, this would lend indirect support to the rational choice approach, but it would not be appropriate to suggest that the rational choice perspective, speaking broadly, had been tested directly.

Holistic views of theory testing, such as Duhem-Quine, make a related argument, which is that disconfirming evidence bears on the whole network of theory, auxiliary assumptions and background knowledge, not merely the hypothesis under test, so that it is ambiguous as to what element or elements of the network have been disconfirmed. Even good and widely accepted evidence rarely selects a theory in crucial-experiment fashion. ${ }^{22}$ In the present case, since the evidence does not refute, the problem seems less Duhem-Quine and more fuzzy testing.

Note that while theoretical ambiguity can result from working at a high level of abstraction - or as the legitimate result of having to take positions on a complex and controversial set of claims regarding human action - ambiguity (or vagueness) can also be a deliberate strategy (like flexible adjustment of auxiliary assumptions) for immunizing theoretical claims against potentially threatening data. But, in either case, we do not need to expect vigorous Popperian winnowing by refutation to believe that even vague theories are not wholly immune to decent evidence.

Consider the data with respect to subjective risk assessment, which fits the inadequate data category. The data are currently too limited to conclusively rule on the accuracy of individuals' risk information, but there is nothing in principle that prevents obtaining better evidence, which may well prove more conclusive. If, for example, it turns out that people do not underestimate the risks of smoking (consistent with Viscusi, 1992), then the hypothesis that people are poorly informed about smoking risks is disconfirmed. A partisan of the non-rational choice view can still retreat behind other defences addiction as incapacitating, for example - but the weight of the evidence will have shifted. Some evidential support will have been produced for the rational choice view. Theoretical refinement is another avenue for progress towards meaningful theory choice, and we take it up next.

\section{A MORE REFINED TAXONOMY OF SMOKING THEORIES}

First, we offer some general speculation on the evidential consequences of greater theoretical refinement, and then we develop a set of more finely differentiated smoking theories, with an eye towards capturing distinctions that may be important. Greater theoretical refinement combats vagueness by 
making theoretical commitments more precise. More precision means greater falsifiability. A more refined hypothesis is more likely to be refuted because it risks more, which is Karl Popper's rationale for bold conjectures. Becker and Murphy's (1988) rational addiction model, for example, requires that longterm price elasticities be greater than short-term, and that more presentoriented persons (youth, the poor, the less educated) be more responsive to price changes. These prediction s clearly risk refutation. ${ }^{23}$

But more precision also involves taking on additional theoretical commitments. These extra commitments themselves require more evidence, because they are new theoretical components subject to appraisal. Becker and Murphy's results, for example, depend on the assumption that preferences are dynamically consistent, which requires a constant discount rate (exponential discounting). Exponential discounting rules out temptation and is thereby inconsistent with ubiquitous and costly self-control practices, such as smoke-ending clinics or purchases by the pack rather than the carton (Schelling, 1984). When there arise competing assumptions, such as hyperbolic discounting (Ainslie, 1975), which permit weakness of will, there is another theoretical front to contest empirically.

Thus, for a given body of evidence, it is ambiguous whether greater refinement makes theory choice easier or harder. With greater refinement, it is more likely that a given theory will have some aspect clearly refuted, but in so doing, there are also more theoretical dimensions to be (empirically) contested. Rival theories will each have refuted aspects, but there are now other fronts on which to fight, as when the hypothetical non-rational choice theorist abandons imperfect information and reverts instead to addiction as incapacitating.

Let us now turn to the matter of more theoretical dimensions among theories of smoking. With greater refinement, theories we have collected under the rational-choice rubric become more differentiated. There are three dimensions we wish to emphasize: (i) stability of preferences; (ii) information; and (iii) computational accuracy.

Becker and Murphy (1988) insist on using the word 'rational' for dynamically consistent preferences, which in turn requires constant exponential discounting. ${ }^{24}$ But whether the discount rate is constant or time-variant seems more of an empirical matter than a postulate of rational choice, and, indeed, the assumption of time invariance was originally made solely for tractability reasons (Loewenstein, 1992). Some would make fixed preferences a postulate of economics. However, there is nothing in rationality as we have defined it that requires fixed preferences, so models that permit preference change can be wholly rational in spirit; that is, they need not imply incompetence or incapacitation (see Loewenstein and Thaler, 1989; O’D onogue and Rabin, 1999). ${ }^{25}$

Nor, in our scheme, does rationality require complete information. To be meaningful, a rational decision clearly requires some information on costs and 
benefits, and it would be non-rational not to use valuable information that one already possesses. But if agents apply rationality to information search, then they will gather information as long as the expected benefits of more information exceed the expected costs. High information costs and low benefits can make some ignorance rational, so rationality, on this reading, does not entail a position on the completeness of information. If smoking risk information has public good aspects, then it may be undersupplied, but this should be seen as a market failure, not a failure of reason.

Computational error or bounded rationality is the third aspect. Decisionmaking resources are scarce, so, analogous to information collection, it can be rational to economize when deciding. This can take the form of 'stopping rules' or decision making rules of thumb. Hence, not all imperfect choices are non-rational when decision making is costly. Of course, thoughtless or sloppy decisions are also common, as are mistakes, so imperfect choice can also be non-rational in nature.

With bounded rationality, even completely informed agents can make mistakes. The psychological literature refers to systematic errors in judgment as 'biases'. Recall the data on subjective risk assessment: if these risk perceptions are incorrect, why are they biased? If people overestimate smoking risks, this is consistent with evidence from the psychological literature that suggests that people tend to overestimate especially well publicized but lower probability events, while underestimating less publicized but higher probability events. Ordinary citizens, for example, generally vastly overestimate the mortality risk of nuclear power accidents, while underestimating the mortality risk of surgery. (See Slovic et al., 1979, cited in Viscusi, 1992: 22-27). Smoking dangers are surely in the 'well-publicized' category.

Or if agents systematically believe that they are less susceptible to risk - the 'I'm immune' bias - this could partially reconcile the divergent findings, since Viscusi asked about dangers 'on average to others', while Shoenbaum asked about risks to oneself. Teenagers are known to regard themselves are relatively immune to risk.

Different assumptions about preference stability, information completeness and decision-making prowess are not 'rational - versus - non-rational dichotomous'. Theories that are rational choice in spirit can and do permit some mutability of preference, different size information sets, and even, if less commonly, bounded rationality.

Table 1 presents alternative theoretical refinements by slightly modifying the preference stability, informational completeness and accuracy, and computational prowess categories. Specifically, it combines information and computational accuracy into one 'computational accuracy' category; preserves the 'stable preference' category, and adds a category 'Is the individual forward looking?'. 
Table 1 Information/preference assumptions about the individual

\begin{tabular}{|c|c|c|c|}
\hline & $\begin{array}{l}\text { Is the } \\
\text { individual } \\
\text { forward- } \\
\text { looking? }\end{array}$ & $\begin{array}{l}\text { Is the individual an } \\
\text { accurate calculator? }\end{array}$ & $\begin{array}{c}\text { Does the individual } \\
\text { have stable } \\
\text { preferences? }\end{array}$ \\
\hline Possibility I & Yes & Yes & Yes \\
\hline Possibility II & Yes & $\begin{array}{l}\text { No: makes flawed } \\
\text { calculations (but has } \\
\text { accurate info) }\end{array}$ & Yes \\
\hline Possibility III & Yes & $\begin{array}{l}\text { No: has inaccurate } \\
\text { information }\end{array}$ & Yes \\
\hline Possibility IV & Yes & $\begin{array}{l}\text { No: has both flawed } \\
\text { info and calculates } \\
\text { incorrectly }\end{array}$ & Yes \\
\hline Possibility V & Yes & Yes & $\begin{array}{l}\text { No: teenager has } \\
\text { different } \\
\text { preferences than } \\
\text { adult (variants } \\
\text { include preference } \\
\text { malleability in } \\
\text { teenagers) }\end{array}$ \\
\hline Possibilities VI-VIII & Yes & $\begin{array}{l}\text { No: information } \\
\text { variation as in } \\
\text { possibilities II } \\
\text { through IV above }\end{array}$ & $\begin{array}{l}\text { No: same as } \\
\text { possibility } \mathrm{V}\end{array}$ \\
\hline Possibility IX & No & $\begin{array}{l}\text { Not meaningful if } \\
\text { not forward looking }\end{array}$ & Yes \\
\hline Possibility X & No & $\begin{array}{l}\text { Not meaningful if } \\
\text { not forward looking }\end{array}$ & $\begin{array}{l}\text { No: same as } \\
\text { possibility V }\end{array}$ \\
\hline
\end{tabular}

We interpret the 10 permutations identified in Table 1 by grouping them into five categories as follows:

Perspective 1, the 'Full Rationality and Stable Preferences Perspective' consists of Possibility I;

Perspective 2, the 'Full Rationality But Changing Preferences Perspective' consists of Possibility V;

Perspective 3, the 'Foresighted but Flawed Rationality and Stable Preferences Perspective' consists of Possibilities II-IV;

Perspective 4, the 'Foresighted but Flawed Rationality and Unstable

Preferences Perspective' consists of Possibilities VI-VIII;

Perspective 5, the 'Myopic Perspective', consists of Possibilities IX-X.

Perspective 5 can be viewed as capturing the 'completely non-rational' individual. The person who chooses imperfectly because of addiction 
effects can be viewed as residing in Perspectives 3 or 4, displaying 'flawed rationality'.

The individual whose preferences while a teenager differ from those he or she has as an adult may fit Possibility V. Many people begin smoking as teenagers, but then, as adults, want to stop smoking. It is at least conceivable that these individuals undergo a preference change (their preferences 'mature') as they age. While this is not the only possible explanation for wanting to quit, it is certainly a possibility.

There are a number of notable features associated with moving from the rational-versus-non-rational dichotomy to this more elaborate specification. First, these five categories better capture important aspects of decision making - information, preference stability, foresight and decision making prowess. Second, the original broad-brush designations 'rational' and 'nonrational' seem now to best apply to Perspectives 1 and 5 respectively. The three categories in between are not readily pigeon-holed into the rational or non-rational choice dichotomy, since imperfect information and bounded rationality are consistent with either. Third, where one sets the dials of preference mutability, information and decision making quality is a theoretical choice that has policy consequences. As one moves away from Perspective 1 - fixed preferences, complete information and optimal choice - the potential scope for and range of paternalistic policy interventions grows larger. Fourth, while we do not spell out the argument here, the empirical evidence reviewed in Section III above does not definitively 'shoot down' any of these five alternatives. UTD is alive and well, even when we move from the broad-brush rational/non-rational dichotomy to these more discriminating hypotheses.

\section{SMOKING POLICY: LIBERAL VERSUS PATERNALIST}

We believe that some aspects of the smoking debate can ultimately be settled by recourse to evidence; in that sense, we are not proponents of strong versions of UTD. ${ }^{26}$ Until that happens, however, there is clearly room to choose among theories by recourse to non-evidential criteria. In social science particularly, ideological preferences may be an important element of these non-evidentiary criteria. An ideological divide particularly relevant for the smoking theory choice is the longstanding and fundamental debate over when the state may intervene to save people from themselves - a.k.a. liberalism versus paternalism - a debate which itself is unlikely to be settled by better data.

Recall the definition of 'hard' paternalism as non-consensual interference in the self-regarding decision-making of a competent adult, interference intended to further that person's welfare (New, 1999). 'Soft' paternalism is reserved for incompetent adults and children. Physicians and public health practitioners are far more positively disposed towards hard paternalism than are economists and other rational choice partisans, who tend to be liberals in 
Mill's sense, believing in maximal liberty consistent with a like liberty for all. Liberals thus see competent adults as the best judge of what's in their own best interest. $^{27}$

With respect to policy, liberals and paternalists agree that minors need to be protected from risky choices like smoking though they may disagree on which intervener - state or parent - is best placed, and perhaps on the appropriate age of majority. They also can agree that smokers should be made accountable for external costs imposed on others - fires, higher insurance premia, environmental tobacco smoke (ETS), etc. But the empirical debate on the external costs of smoking, and a related dispute over the appropriate unit of appraisal - a household or an individual - reveal more fundamental differences.

The first comprehensive estimates of external costs took the household as the unit of appraisal (thus ignoring costs borne by in vivos non-smokers, including fetuses), and ignored ETS costs. Manning et al. (1991), for example, estimated external costs to be roughly $\$ 0.33$ per pack (rendered in 1995 dollars), which roughly comports with Viscusi's 1995 analysis. ${ }^{28}$ Hanson and Logue (1998) vehemently disagree, and estimate per pack external costs at $\$ 7.00$.

But disagreements on definition - should fetuses and spouses be counted in calculating external costs, should ETS be counted - involve relatively small costs per pack and thus are not what lead to the enormous disparity between the liberal and paternalist estimates of external costs. Hanson and Logue's (the paternalists) external cost estimate is higher because they include as 'external' costs those costs that smokers impose on themselves (\$6.00), and because they refuse to consider as external benefits the lower pension payments, and lower nursing home care expenditures that result from smokers dying earlier. It is these two assumptions that explain the different estimates. Furthermore, both assumptions derive from a disagreement over how one should best conceive of social welfare.

A public heath perspective treats longer life as an unmitigated social benefit, whereas economists regard it as a private benefit (Warner et al., 1995). On the public health view, then, policies that extend life are a social good, period. Conversely, if a behaviour risks shortening life, it is bad. In this sense, the public health view of welfare is unavoidably paternalistic, since it cannot abide any decision that risks shorter life, (and must support a policy that extends life), and because it assumes that individuals cannot sensibly want to trade off length of life for quality of life. Traditional religious or ethical paternalism says, if it's bad, the law must proscribe it'. Public health paternalism merely substitutes 'risky' for 'bad'. Harris (1993), a physician and self-described 'warm' economist active in the anti-smoking movement, regards economics as 'cold' when it insists that self-inflicted costs are not social, or when it counts lower social costs from premature death as 
social benefits. ${ }^{29}$ On his view, which is the public health view, the economist's consequentialist social accounting is immoral; deontologically impermissible.

Of course, one can support anti-smoking policies without recourse to the hard paternalism embedded in the public-health view of social welfare. A version of the primose-path argument, for example - many smokers get addicted as minors - is not incompatible with the rational choice paradigm. Most rational choice theorists do not object in principle to protecting minors. ${ }^{30}$ Rational choice theorists are less comfortable with the idea of addiction as incapacitating, but can accept the idea that minors are unlikely to adequately anticipate the risk of addiction, or the cost of withdrawal.

This exception noted, it seems clear that paternalist scholars like Harris and Hanson and Logue are prepared to go beyond market failure remedies or exceptions for children in order to save informed adults from themselves, whereas liberals are not. Consider another illustration of this divide (from Leonard et al., 2000), where a paternalist and a liberal view information in fundamentally different ways. The case is disinformation. A paternalistic public health official who believes that even well informed adult smokers exhibit a failure of reason might endorse a policy of greatly exaggerating the risks of smoking, as a means to the end of smoking reduction. Since the paternalist's goal is not to inform per se, but to promote paternalized persons' welfare as she sees it, disinformation can be consistent with paternalism. For the liberal, in contrast, a policy of disinformation is incoherent, because the liberal's goal is to inform - to provide missing information-not to produce a particular outcome. For the liberal, fraud, even well intended fraud, cannot be justified, as it cannot improve self-regarding individual choices. ${ }^{31}$

\section{CONCLUSION}

Upon beginning this paper we believed that smoking behaviour would prove an instructive case study of UTD. The domain of study - smoking behaviour is narrowly focused, and there is excellent and widely accepted empirical evidence. Examining this case has generated a number of relevant findings. First, an appropriate characterization of rival theories (or perspectives) is difficult. We started with a broad-brush dichotomous distinction between rational choice and non-rational choice perspectives, later finding that a more refined classification was more accurate. With respect to theory choice, we also found that, at least for a given body of evidence, it is ambiguous whether greater refinement helps or hinders determining the better theory.

Second, whether we use the rational-non-rational distinction or the more refined five-category classification, the UTD problem is present. Even with good evidence, one cannot show that one of the perspectives definitively dominates all of the others, given our current state of information and knowledge about smoking. However, some of this UTD may well be temporary (so that it is not strong UTD). That is, it 
could conceivably be resolved, at least in part, with the development of more decisive evidence.

Yet even if evidential support were to clearly tip the balance in favour of one theory over the others, there would likely remain a normative divide between liberals and paternalists with respect to the proper role of government in smoking policy, a divide that itself seems unbridgeable even with the advent of better evidence.

Third, it is interesting to speculate on why UTD is present even in this promising case. Smoking behaviour is indeed narrow in domain, but very broad in the sense that it requires taking positions on fundamental (and thus contested) aspects of human behaviour: stability of preferences, information completeness, foresightedness and computational prowess. The data are very good, but not yet adequate to adjudicate across the many different fronts opened up by the theoretical commitments required. And, to the extent that the theories in question are 'malleable' and theorists are adept at accommodating anomalous data, a remarkably wide range of hypotheses can be rescued: Suranovic et al. (1999) and Goldbaum (2000) show how regret is compatible with a rational choice approach, and Becker (1962) shows how irrational consumers can obey the law of demand. Finally, when rival perspectives generate shared implications - such as the appropriateness of protecting minors from risky choices - reasonable observers should want to consider these conclusions especially seriously, since they are robust to changes in theoretical perspective.

Robert S. Goldfarb and Steven M. Suranovic George Washington University, USA gldfrb@gwu.edu,smsuran@gwu.edu

Thomas C. Leonard

Princeton University

tleonard@princeton.edu

\section{ACKNOWLEDGEMENTS}

The authors wish to thank Mary Ann Baily, Roger Backhouse, Dean Farley and Judith Wilkenfeld for comments on earlier drafts. We also received helpful comments, some of them noted below, at presentations at the EEA meetings, Boston, March 1999, and the INEM meetings, Vancouver, June 2000 .

\section{NOTES}

1 Every year about 430,000 citizens die prematurely from cancers, cardiovascular disease and stroke, and many more suffer from bronchitis, emphysema and other chronic conditions (CDC, 1993). 
2 There is a resemblance to Bloor's (1976) symmetry principle, which says that sociologists should use the same causal accounts to explain scientific beliefs, regardless of whether those beliefs are true or false. By itself, this injunction requires only that the sociologist of science remain methodologically agnostic on the question of truth versus falsity. In practice, however, the symmetry principle is routinely read as requiring that only social causes can be used to explain what scientists believe.

3 Laudan and Leplin (1991) argue that strong UTD proponents make a mistake: UTD does not follow from empirical equivalence unless empirical consequences are improperly identified with evidential support. Laudan and Leplin argue that evidential support for a theory is not limited to instances that are the direct consequences of it, so that epistemologically warranted choices among rivals are still possible. One way is indirect evidential support. Consider two empirically equivalent hypotheses $\left(H_{1}\right.$ and $\left.H_{2}\right)$, where only $H_{1}$ is derivable from a more general theory $T$, which also implies another hypothesis $H$. Empirical consequence $(E)$ of $H$ is observed repeatedly (many instances), which supports $H$ and thereby $T$, also lending indirect evidential support for $\mathrm{H}_{1}$ but not $\mathrm{H}_{2} . E$ is not a consequence of $\mathrm{H}_{1}$ or $\mathrm{H}_{2}$ but nonetheless offers an evidential basis for preferring $\mathrm{H}_{1}$, ceteris paribus. (Laudan and Leplin, 1991: 464).

Laudan and Leplin also argue for the converse, which is that empirical instances of the consequences of a theory do not necessarily provide evidential support. If our hypothesis is that massive doses of coffee cure colds, and our 'evidence' finds that 100 subjects who drank coffee for three weeks no longer had colds, there are 100 positive instances of the empirical consequences of our hypothesis. But no one would regard the data as offering much evidential support for the coffee cure. Indeed, the idea of experimental control groups arises precisely because we do not accept all positive instances as confirming instances. Hence, results that test a theory, and results that are obtainable as consequences of a theory are partially overlapping sets, but they are not identical (Laudan and Leplin, 1991: 466), so strong UTD does not follow even when empirical equivalence is granted.

4 Suppose the only criterion for theory choice says 'pick the theory with the largest set of confirming instances', and that there are two rival theories with an equal number of confirming instances. Under these circumstances choice is indeterminate. This example is due to Laudan (1990: 286).

5 The term 'addiction' no longer has, if it ever had, a widely accepted standard clinical definition. Various definitions invoke one or more of the following: tolerance (the need for larger doses to achieve the same effect); withdrawal (pain from reducing or ceasing consumption); compulsive consumption even with adverse consequences; and intoxication. With respect to smoking, we employ the term as a kind of shorthand for habitual use with withdrawal effects. See Elster and Skog (1999) for more on rationality and addiction.

6 Sticking to a low-fat diet and maintaining an adequate exercise regimen can reduce mortality risk nearly as much as not smoking (McGinnis and Foege, 1993). Casual empiricism and obesity rates suggest that these goals are often as hard to achieve as quitting smoking.

7 With the exception of this class of models, it is rare to find formal models displaying non-rational choice approaches. In part, this is because most nonrational choice theorists come from intellectual traditions that typically do not employ the formal modelling techniques so ubiquitous in economics.

8 In the medical literature on addiction, involuntary choice is sometimes referred to as a disease process, a view that using addictive substances causes biological changes in the brain, as evidenced by brain imaging technology (see Satel 1999). 
9 For example, good theories should: increase understanding of phenomena (Steven Toulmin); predict phenomena accurately (Milton Friedman) . . . ; always be expressible in the notation of formal logic (A.J. Ayer); be chosen based on their relative expected profitability (Charles Sanders Peirce); . . . Have survived criticism (William Bartley); . . be persuasive (D. McCloskey); . . a aim for empirical adequacy (Bas van Fraassen): . . . ; be falsifiable . . . (Karl Popper)' (Leonard, 1997: 27).

10 Empirical studies by Townsend (1987), Becker et al. (1991, 1994), Chaloupka (1991), and Farrelly and Bray (1998), among others, find that consumption is sensitive to changes in price. Viscusi (1992: 102-105) tabulates 41 studies that estimate price elasticities. The short-run elasticities consistently cluster around -0.4 . There is also evidence of differential price effects. Younger smokers, for example, appear to be more responsive to increases in cigarette prices (Farrelly and Bray, 1998). Viscusi (1995) suggests that teenage consumption elasticities are in the range of -1.2 to -1.4 . Chaloupka and Grossman (1996) concur; they estimate a price elasticity of youth demand for cigarettes of -1.313 . Similar summary readings of the elasticity estimation literature appear in Adams and Brock (1999: 64-9).

11 Sufficient, that is, for normal goods and for inferior goods with small income effects. Income elasticity evidence suggests that cigarettes are normal goods.

12 One time-honored response is to argue that transactions data are superior to survey data - what people actually choose is evidentially more reliable than what they say they would choose. Viscusi, for example, points out that half of Los Angeles residents say they want to move, while a vastly smaller number actually do (1992: 120). Scepticism with respect to survey (as against transactions) data is a familiar methodological stance among economists (see Boulier and Goldfarb, 1998).

13 If the regretful smoker means 'I prefer quitting to smoking and yet I choose to smoke', he truly prefers $x$ to $y$ and chooses $y$ - then this is more problematic for rational choice theories. The possible explanations are: (i) the choice is not meaningful, the desire for $y$ is so overwhelming as to be non-volitional (incapacitation); (ii) preferences change between decision and execution; or (iii) preferences are not singularly ordered, as, for example, in schemes that permit meta-preferences (see, for example, George, 1998).

14 'Harvard biochemist Bertha Madras acknowledges a virtual library of documented, replicable brain changes with drug exposure, but she also points out that there are no scientific studies correlating them with behaviour. John B. Seibyl, a psychiatrist and nuclear radiologist at Yale University School of Medicine has called the notion of predicting behaviour from brain pathology "modern phrenology", (Satel, 1999: 54).

15 Relapse rates are high for addicts who go to clinics or other treatment facilities, but relying on these data may introduce a selection bias, since most addicts don't go to clinics, and relapse rates among the non-clinic addicts are far lower (Heyman in Lambert, 2000: 67).

16 A CDC survey of 20000 adults found that about one third of smokers try to quit in a given year, and that only eight percent of these quit attempts succeed (Hanson and Logue, 1998: 1193, 1199). In 1980, about 40\% of smokers reported three or more lifetime attempts to quit; and about half of former smokers report three or more attempts before success, where 'success' is defined as no cigarettes in the previous two years. But many smokers do shake the habit. For example, half of all Americans who have ever smoked have successfully quit, over 50 million people (Schelling, 1992). 
17 It is also argued that prospective smokers underestimate the likelihood (and perhaps the cost) of becoming addicted. We do not consider this argument separately, on ground s that it is of a piece with health risk information accuracy.

18 The youngest age group (ages 16-21) was found to have the highest risk perceptions, consistent with the fact that this cohort has received a higher fraction of health messages (Viscusi 1992: 72-3).

19 According to Viscusi, the best scientific estimates put smoking mortality risk between 0.18 and 0.36 . The average respondent, however, assayed the risk at 0.54 , and, here again, even current smokers overestimated the true risk at 0.47 (Viscusi, 1992: 77). Interviews with 3669 smokers found that $83 \%$ of smokers (87\% of those aged 25-34) thought it was 'very likely' or 'likely' that by quitting they would avoid or decrease serious health problems from smoking. Eighty-five per cent of smokers disagreed that little health benefit exists from quitting for a person who has smoked greater than 20 years (CDC, 1990).

20 Schoenbaum took data on peoples' beliefs about their likelihood of reaching age 75 from the Health and Retirement Survey, a national probability sample of adults age 50 through 62 . These expectations were compared with epidemiological predictions from life-tables for never, former, current light and current heavy smokers. The life tables were constructed from the 1986 National Mortality Followback Survey and the 1985 and 1987 National Health Interview Surveys.

21 It can also be argued that probability estimates elicited from individuals may not be useful, because many people do not think in probability terms, and therefore do not base decisions on explicit probability calculations. Thus, numerical probabilities elicited from them may not represent meaningful measures of their perception of smoking risks. We owe this point to Mark Blaug.

22 In commenting on an earlier version of this paper, Roger Backhouse argued that empirical evidence rarely if ever has its effect in the form of a 'knockdown test'. Instead, the weight of empirical evidence tends in some cases to slowly 'accrete', so that, over time judicious observers come to believe that empirical evidence weighs more heavily in favour of a particular view. It seems to us that the accumulating evidence over several decades of the negative health effects of smoking is an example fitting this description.

23 If, for example, David Kessler had hypothesized that addiction implies that aggregate cigarette consumption is wholly unresponsive to higher prices, then the fact of downward sloping demand would be a refutation. But Kessler's claim, recall, was that 'most smokers are in effect deprived of the choice to stop smoking' (emphases added). The modifiers 'most' and 'in effect' are sufficient to ensure that his claim is consistent with the evidence. We do not suggest that Kessler is deliberately using weasel words, for it is unlikely he believes cigarette demand curves are vertical.

24 A time-consistent choice requires that the relative preference for consumption at an earlier date over a later date be invariant over time. Preferring one drink today to two drinks tomorrow, requires the time-consistent person to prefer one drink a year from now to two drinks in a year plus a day. Time inconsistency arises if two drinks in 366 days is preferred today, but is reconsidered when the smaller but earlier option proves more tempting. (Adapted from Thaler, 1981).

25 Related approaches, which allow ambivalence or 'multiple selves', do not require preferences to be ordered along a single metric. Such approaches can also entail preference change, as different selves compete internally (see, e.g. Thaler and Sheffrin, 1981; Schelling, 1984; Elster 1986).

26 Indeed, strong UTD puts the theorist of science in a reflexive bind: what, after all, 
is the point of gathering evidence when you've already decided that evidence is always immaterial?

27 'Best' does not mean perfect; lapses from good judgment are common and open the door to paternalistic interveners. But such lapses, on the liberal view, are not by themselves sufficient for paternalism. Also required is evidence that the state is better placed than the paternalized person (and any other interveners), and that intervention does more good than harm. (For more on these points, see Leonard et al., 2000.)

28 The most comprehensive study on the costs of smoking (Manning et al., 1989, $1991)$ carefully computes and itemizes external costs per pack smoked. Smokers consume medical care $(\$ 0.26)$ and sick leave $(\$ 0.01)$ beyond what they pay for; they raise the cost of life insurance premiums $(\$ 0.05)$; cause fires $(\$ 0.02)$, and pay fewer taxes $(\$ 0.09)$ by dying prematurely. On the other hand, premature death also saves society part of the cost of providing pensions $(-\$ 0.24)$ and nursing home care $(-\$ 0.03)$. The total net external costs per pack is therefore 15 cents (in 1986 dollars, with $\$ 0.01$ rounding error). Updated to 1995 prices, the per pack external cost is $\$ 0.33$. In 1995 , a verage excise taxes were $\$ 0.50$ per pack $(\$ 0.24$ Federal, the balance state and local). On this estimate, then, external costs created by smokers are exceeded by the taxes they pay.

29 Regarding the latter, Harris says: 'this is not the kind of calculation that a civilized society engages in'. (1993).

30 One survey finds that $53 \%$ of ever-daily smokers (which includes once daily smokers who've since quit) became daily smokers before age $18,77 \%$ before age 20 (CDC, 1994: 65).

31 Ross Emmett made the intriguing suggestion that, just as we 'unpacked and expanded' the rational/non-rational dichotomy into five categories with 'closer' borders, the paternalism/liberalism dichotomy might itself be subject to such an unpacking. This would allow more fruitful discussion across these 'closer' borders, and could, thereby, even weaken our claim of strong conceptual disagreement. Pursuing this provocative suggestion is beyond the scope of this paper.

\section{REFERENCES}

Adams, W. and Brock, J. (1999) The Tobacco Wars, Cincinnati: South-Western College Publishing Co.

Ainslie, G. (1975) 'Specious reward: a behavioral theory of impulsiveness and impulse control', Psychological Bulletin 82: 463-509.

Becker, G.S. (1962) 'Irrational behavior and economic theory', Journal of Political Economy 70: 1-13.

Becker, G., Grossman, M. and Murphy, K. (1994) 'An empirical analysis of cigarette addiction', American Economic Review 84: 396-418.

Becker, G., Grossman, M. and Murphy, K. (1991) 'R ational addiction and the effect of price on consumption', American Economic Review 81: 237-41.

Becker, G.S. and Murphy, K. (1988) 'A theory of rational addiction', Journal of Political Economy 96: 675-700.

Bloor, D. (1976) Knowledge and Social Imagery, London: Routledge and Kegan Paul.

Boulier, B. and Goldfarb, R.S. (1998) 'On the use and non-use of surveys in economics', Journal of Economic Methodology 5: 1-21.

Centers for Disease Control (CDC) (1993) 'Cigarette smoking-attributable mortality and years of potential life lost - United States, 1990', Morbidity and Mortality Weekly Report 42: 645-9. 
Centers for Disease Control (CDC) (1990) 'Perspectives in disease prevention and health promotion: smokers' beliefs about the health benefits of smoking cessation - 20 U.S. Communities, 1989', Morbidity and Mortality Weekly Report 39: 653-6.

Chaloupka, F. (1991) 'Rational addictive behavior and cigarette smoking', Journal of Political Economy 99: 722-42.

Chaloupka, F. and Grossman, M. (1996) 'Price, tobacco control policies, and youth smoking', NBER Working Paper No. 5740, National Bureau of Economic Research, Cambridge, MA.

Chaloupka, F. and Warner, K. (1999) 'The economics of smoking', NBER Working Paper No. W7047, National Bureau of Economic Research, Cambridge, MA.

Collins, H. (1981) 'Stages in the empirical programme of relativism', Social Studies of Science 11: 3-10.

Collins, H. and Yearly, S. (1992) 'Journey into space', in A. Pickering (ed.) Science as Practice and Culture, Chicago: University of Chicago Press, pp. 369-89.

Cross, R. (1998) 'The Duhem Quine hypothesis', in J.B. Davis et al. (ed.) The Handbook of Economic Methodology, Cheltenham: Edward Elgar, pp. 107-10.

Elster, J. (ed.) (1986) The M ultiple Self, Cambridge: Cambridge University Press.

Elster, J. and Skog, O.-J. (eds) (1999) Getting Hooked: Rationality and Addiction, Cambridge: Cambridge University Press.

Farrelly, M.C. and Bray, J.W. (1998) 'Response to increases in cigarette prices by race/ ethnicity, income, and age groups - United States, 1976-1993', Morbidity and Mortality Weekly Report 47: 605-09.

George, D. (1998) 'Coping rationally with unpreferred preferences', Eastern Economic Journal 24: 181-194.

Goldbaum, D. (2000) 'Life cycle consumption of a harmful and addictive good', Economic Inquiry 38: 458-69.

Gravelle, J. and Zimmerman, D. (1994) 'Cigarette taxes to fund health care reform: an economic analysis', Congressional Research Service No. 94-214E, March 8, 1994.

Hanson, J. and Logue, K. (1998) 'The costs of cigarettes: the economic case for incentive-based regulation', Y ale Law Journal 107: 1163-1361.

Harris, J. (1993) Testimony before the Committee on Ways and Means, U.S. House of Representatives, in Public Hearings on the Financing Provisions of the Administration's Health Security Act, November 18, 1993, http://web.mit.edu/jeffrey/harris/ testimony.html.

Herrnstein, R. and Prelec, D. (1992) 'Melioration', in G. Loewenstein and J. Elster (eds) Choice over Time, New York: Russell Sage.

Klein, R. (1993) Cigarettes are Sublime, Durham, NC: Duke University Press.

Lambert, C. (2000) 'D eep cravings', Harvard Magazine: 61-68.

Latour, B. (1987) Science in Action, Cambridge, MA: Harvard University Press

Laudan, L. (1990) 'Demystifying underdetermination', in C. Wade Savage (ed.) Minnesota Studies in the Philosophy of Science, volume XIV, Minneapolis, MN: University of Minnesota Press, 267-97.

Laudan, L. and Leplin, J. (1991) 'Empirical equivalence and underdetermination', Journal of Philosophy 88: 449-72.

Leonard, T.C. (1997) 'The reason of rules in the intellectual economy: the economics of science and the science of economics', PhD Dissertation, George Washington University, September 1997.

Leonard, T., Goldfarb, R. and Suranovic, S. (2000) 'New on paternalism and public policy', Economics and Philosophy 16: 323-31.

Loewenstein, G. (1992) 'The fall and rise of psychological explanations in the 
economics of intertemporal choice', in G. Loewenstein and J. Elster (eds) Choice Over Time, New York: Russell Sage Foundation, pp. 3-34.

Loewenstein, G. and Thaler, R. (1989) 'Anomalies: intertemporal choice', Journal of Economic Perspectives 3: 181-93.

Manning, W. et al. (1989) 'The taxes of sin: do smokers and drinkers pay their way?', Journal of the American Medical A ssociation 261: 1604-9.

Manning, W. et al. (1991) The Costs of Poor Health Habits, Cambridge, MA: Harvard University Press.

McGinnis, J.M. and Foege, W.H. (1993) 'Actual causes of death in the United States', Journal of the American Medical A ssociation 270: 2207-12.

New, B. (1999) 'Paternalism and public policy', Economics and Philosophy 15: 63-83.

O'D onoghue, T. and Rabin, M. (1999) 'Doing it now or later', American Economic Review 89: 103-24.

Orphanides, A. and Zervos, D. (1995) 'Rational addiction with learning and regret', Journal of Political Economy 103: 739-58.

Pollak, R. (1975) 'The intertemporal cost of living index', Annals of Economic and Social Measurement 4: 179-95.

Quine, W. (1953) 'Two dogmas of empiricism', in From A Logical Point of View, Cambridge, MA: Harvard University Press, pp. 20-46.

Satel, S. (1999) 'The fallacies of no-fault addiction', The Public Interest 134: 52-67.

Schelling, T. (1992) 'Addictive drugs: the cigarette experience', Science 255: 430-33.

Schelling, T. (1984) 'Self command in practice in policy and in a theory of rational choice', American Economic Review 74: 1-11.

Schoenbaum, M. (1997) 'Do smokers understand the mortality effects of smoking? Evidence from the health and retirement survey', A merican Journal of Public Health 87: 755-59.

Slovic, P., Fischoff, B. and Lichtenstein, S. (1979) 'Rating the risks', Environment 21: 14-39.

Sullum, J. (1997) 'Blowing smoke about addiction', Houston Chronicle.

Suranovic, S., Goldfarb, R. and Leonard, T. (1999) 'An economic theory of cigarette addiction', Journal of Health Economics 18, 1-29.

Thaler, R. (1981) 'Some empirical evidence on dynamic inconsistency'. Economic Letters 8: 201-207.

Thaler, R. and Sheffrin, H. (1981) 'An economic theory of self-control', Journal of Political Economy 89: 392-410.

Townsend, J.L. (1987) 'Cigarette tax, economic welfare, and social class patterns of smoking', Applied Economics 19: 355-65.

U.S. Agency for Health Care Policy and Research (AHCPR) (1998) 'Research activities', No. 215 (May).

United States Department of Health and Human Services (USDHHS) (1982) The Health Consequences of Smoking: Cancer. A Report of the Surgeon General (82-50179), Washington DC.

van Fraassen, B. (1980) The Image of Science, New York: Oxford University Press.

Viscusi, W.K. (1995) 'Cigarette taxation and the social consequences of smoking', in James Poterba (ed.) Tax Policy and the Economy.

Viscusi, W.K. (1992) Smoking: Making the Risky Decision, New York: Oxford University Press.

Warner, K. (1999) 'Review of Jacob Sullum For Your Own Good: The Anti-Smoking Crusade and the Tyranny of Public Health', The New England Journal of Medicine, 340.

Warner, K. et al. (1995) 'Criteria for determining and optimal cigarette tax: the economists perspective', Tobacco Control 4: 380-6. 